\title{
Preventive Healthcare Use, Smoking, and Alcohol Use among Rhode Island Women Experiencing Intimate Partner Violence
}

\author{
STEPHENIE C. LEMON, Ph.D., ${ }^{1}$ WENDY VERHOEK-OFTEDAHL, Ph.D., ${ }^{1}$ \\ and EDWARD F. DONNELLY, R.N., M.P.H. ${ }^{1,2}$
}

\begin{abstract}
Objective: Intimate partner violence (IPV) poses major health threats to women, including increased risk for several chronic health conditions. The impact of IPV on use of preventive health services is not well understood. Although several studies indicate that female victims of IPV have higher rates of alcohol abuse, this has not been replicated in population-based studies. The association of IPV with smoking has not been a major research focus. The purpose of this study was to examine the association between physical and psychological IPV in the past 12 months and preventive healthcare use, smoking, and alcohol use among women.

Methods: Data on 1643 women aged 18-54 from the 1999 Rhode Island Behavioral Risk Factor Surveillance System were analyzed. Logistic regression, controlling for age, race, marital status, education, insurance status, and functional disability, was used to model the associations of IPV with (1) checkups, (2) clinical breast examinations (CBEs), (3) Pap smear screening, (4) cigarette smoking, and (5) high-risk alcohol use.

Results: Prevalence of physical IPV was $4.1 \%$. The prevalence of psychological IPV, in the absence of physical IPV was $4.5 \%$. Physical IPV was associated with receiving regular Pap smears odds ratio $([\mathrm{OR}]=2.39,95 \%$ confidence interval $[C I] 1.01-5.70)$, current smoking (OR $=2.07,95 \%$ CI 1.03-4.18), and high-risk alcohol use (OR $=4.85,95 \%$ CI 2.02-11.60). Psychological IPV was associated with high-risk alcohol use (OR = 3.22, 95\% CI 1.46-7.09).

Conclusions: Women experiencing IPV regularly access preventive healthcare, providing healthcare providers with opportunities to assess and counsel women for IPV in addition to smoking and high-risk alcohol use.
\end{abstract}

\section{INTRODUCTION}

I NTIMATE PARTNER VIOLENCE (IPV) is a major public health concern in the United States, with women at significantly greater risk of victimization than men. ${ }^{1}$ In addition to victimization by physical abuse, women also suffer from sexual coercion and assault, physical intimidation and threats, verbal assault and emotional abuse, and control over daily activities by intimate partners. ${ }^{2}$ Approximately 1.8-4 million women in the United States are physically abused by their partners annually. ${ }^{3}$ Population-based studies have estimated that $2 \%-6 \%$ of women are the victims of

\footnotetext{
${ }^{1}$ Department of Community Health, Brown University School of Medicine, Providence, Rhode Island.

${ }^{2}$ Rhode Island Department of Health, Providence, Rhode Island.

Data collection for this study was supported by the Centers for Disease Control and Prevention Cooperative Agreement U17/CCU 111076.
} 
severe physical IPV every year. ${ }^{1,4-6}$ Estimates of total IPV, defined as either physical or psychological, are considerably higher, ranging from $8 \%$ to $12 \%$ annually. ${ }^{7}$

Acute physical injuries, including broken bones, concussions, and bruises, are common consequences of IPV, 8,9 and victims of IPV frequently use emergency medical services for such acute medical conditions. ${ }^{10-14}$ However, women who are victims of IPV are also at risk for many chronic health problems, ${ }^{15}$ including chronic pelvic pain, ${ }^{16}$ gastrointestinal symptoms, ${ }^{17}$ and chronic headaches. ${ }^{18}$ Victims of sexual assault often experience vaginal and perineal trauma ${ }^{19}$ and are at greater risk of contracting sexually transmitted diseases (STDs). ${ }^{20-22}$

Studies conducted in medical care settings suggest that physical IPV is common among women who use ambulatory healthcare services. ${ }^{23-28}$ However, there are few population-based studies assessing the association between IPV and preventive health services. ${ }^{6,29,30}$

Women who are victims of IPV have much greater rates of substance abuse, including alcohol abuse, compared with women who are not IPV victims. ${ }^{25,31,32}$ However, research in this area has relied largely on convenience samples. The association of IPV with tobacco use has become a focus of research only recently, with women who are current smokers more likely to report IPV. $6,30,33$

The purpose of this study is to determine the relationship of IPV to utilization of three preventive medical services, routine checkups, Pap smears, and clinical breast examinations (CBE), and two negative health-related behaviors, current smoking and high-risk alcohol use.

\section{MATERIALS AND METHODS}

\section{Study population}

Data for this study were obtained from the 1999 Rhode Island Behavioral Risk Factor Surveillance System (BRFSS). The BRFSS is an annual random digit-dialed telephone survey of noninstitutionalized adults aged 18 and over that collects information on a wide range of health-related behaviors, healthcare use, and health status. The 1999 RI BRFSS included a series of questions concerned with IPV. The response rate for the 1999 RI BRFSS was 57\%, which was calculated using the Council of American Survey Research Organizations criterion, ${ }^{34}$ which is computed as the number of persons who completed the survey divided by the number of known eligible persons plus a proportion of households that were not contacted that were assumed to include an eligible person. Only one adult per household was sampled. Information on nonresponders was not available, so comparisons between responders and nonresponders could not be made.

Of the 4003 persons in the 1999 RI BRFSS, 2442 $(61 \%)$ were women. Age was reported for 2411 $(99 \%)$. Women ages 55 and over $(n=768)$ were excluded because prevalence of IPV among older women was very low (0.6\% physical IPV, 1.9\% psychological IPV). Of the 1653 women ages 18-54, complete information on IPV was available for 1561 women (95\%), which was the sample used in this analysis. This study was determined to be exempt by the Brown University and RI Department of Health Internal Review Boards.

\section{Measures}

Intimate partner violence. IPV assessment questions were developed by the Centers for Disease Control and Prevention (CDC) and pretested by the RI Department of Health. History of IPV in the past 12 months was defined hierarchically as any physical or sexual IPV, psychological IPV in the absence of physical or sexual IPV, or no IPV. Women who reported being pushed, slapped, hit, punched, shaken, kicked, choked, being made to take part in any unwanted sexual activity, or otherwise physically harmed by an intimate partner within the previous 12 months were considered victims of physical IPV. Women who reported no physical or sexual IPV but reported feeling frightened because of threats or anger of an intimate partner or feeling that an intimate partner tried to control most or all of the woman's daily activities in the prior 12 months were considered victims of psychological IPV.

Preventive healthcare use, smoking, and alcohol use. The preventive healthcare use outcomes of interest in these analyses were receiving a current checkup, Pap smear, and CBE. Each was a binary (yes/no) variable. Women who indicated receiving a checkup, Pap smear, and CBE within the previous year were defined as current for each. ${ }^{35}$ Women who reported never having one or not 
having one in the previous year were defined as not current.

Respondents were considered current smokers if they first reported ever smoking 100 cigarettes in their lifetime and then reported that they currently smoke. Current smokers were compared to never and former smokers (yes/no). High-risk alcohol use was defined as consuming on average three or more alcoholic drinks per occasion at least one time per week in the previous year. ${ }^{36}$ Those who did not meet this criterion were not considered high-risk alcohol users. High-risk alcohol users were compared with those who were not high-risk users.

Demographics and functional limitations. Several sociodemographic characteristics were controlled for as potential confounders of the association between IPV and the five dependent variables under study. These included age, race/ethnicity, marital status, educational level, and insurance status. Income information was missing for more than half of this sample. Therefore, this variable could not be analyzed. Functional disability was also assessed. Respondents were asked if because of any impairment or health problem, they were limited in the kind or amount of work they were able to do; limited in any activities; had any trouble learning, remembering, or concentrating; or needed special equipment. Those who answered yes to any question were considered to have functional disability.

\section{Statistical analyses}

Univariate analyses were performed to describe the study sample. Bivariate contingency tables were generated to describe the prevalence of both IPV types among covariate subgroups. We then fit a multivariable multinomial logistic regression model, which simultaneously assessed the association of each covariate with IPV types compared with those who reported experiencing no IPV.

The association of IPV and each dependent variable was then assessed. Bivariate contingency tables were first generated to estimate the prevalence of each dependent variable among each classification of IPV. We then fit logistic regression models to assess the association of IPV with each outcome variable. Each covariate was retained in the model as a potential confounder.

The RI BRFSS dataset includes weights to cor- rect for differential probability of selection into the study sample. All analyses presented were weighted using SUDAAN statistical software (Version 7.5.2, Research Triangle Institute, NC).

\section{RESULTS}

\section{Univariate statistics}

Physical IPV was reported by $4.1 \%$ of women in the sample. Psychological IPV in the absence of physical IPV was reported by an additional $4.5 \%$ of the sample. A regular checkup was reported by $85 \%$, current Pap smear by $77.5 \%$, and current CBE by $71.8 \%$ of the women in the sample. High-risk alcohol use was reported by $7.8 \%$ of respondents, and $29.3 \%$ were current smokers. A description of the demographic characteristics and functional disability of the sample is presented in Table 1.

\section{Factors associated with IPV}

Presented in Table 1 are the associations of each demographic characteristic and functional disability with IPV status. In the multivariable multinomial logistic regression model, compared with those who reported experiencing no IPV, those who experienced physical or sexual IPV or both were more likely to be ages 18-29 (OR $=6.10,95 \%$ CI 2.38-15.64) or ages 30-44 (OR $=2.65,95 \%$ CI $1.10-6.42)$, to be divorced or separated $(\mathrm{OR}=4.85$, 95\% CI 2.23-10.52), and to report having functional disability (OR $=3.25,95 \%$ CI 1.65-6.43). Compared with those who reported experiencing no IPV, those who experienced psychological IPV were more likely to be ages $18-29$ (OR $=2.86,95 \% \mathrm{CI}$ $1.24-6.59)$, to never have been married $(\mathrm{OR}=2.06$, 95\% CI 1.13-1.93), to have less than a high school $(\mathrm{OR}=3.11,95 \%$ CI 1.25-7.76), to be uninsured $(\mathrm{OR}=2.84,95 \%$ CI 1.28-6.33), and to report having functional disability $(\mathrm{OR}=2.39,95 \% \mathrm{CI}$ 1.31-4.38). Persons of nonwhite race were less likely to report experiencing psychological IPV $(\mathrm{OR}=0.23,95 \%$ CI $0.09-0.64)$.

\section{Association of IPV with preventive healthcare} use, smoking and alcohol use

Among those who reported experiencing no IPV , 84.8\% had a recent checkup, compared with $81.6 \%$ who reported physical or sexual IPV and 
Table 1. Study Characteristics, Prevalence of Intimate Partner Violence According to Study Characteristics, and Adjusted Multinomial Logistic Regression Models among Rhode Island Women in 1999

\begin{tabular}{|c|c|c|c|c|c|}
\hline & \multirow[b]{2}{*}{$\begin{array}{c}\text { Total sample } \\
\%\end{array}$} & \multicolumn{2}{|c|}{ Physical/sexual IPV a } & \multicolumn{2}{|c|}{ Psychological IPV only ${ }^{\text {a }}$} \\
\hline & & $\begin{array}{l}\text { \% of subgroup } \\
\text { experiencing }\end{array}$ & OR $(95 \% \mathrm{CI})$ & $\begin{array}{l}\text { \% of subgroup } \\
\text { experiencing }\end{array}$ & OR $(95 \% \mathrm{CI})$ \\
\hline \multicolumn{6}{|l|}{ Age, years } \\
\hline $18-29$ & 30.7 & 6.7 & $6.10(2.38-15.64)$ & 8.6 & $2.86(1.24-6.59)$ \\
\hline $30-44$ & 45.5 & 3.3 & $2.65(1.10-6.42)$ & 4.4 & $1.81(0.84-3.94)$ \\
\hline $45-54$ & 23.8 & 1.4 & 1.0 & 2.4 & 1.0 \\
\hline \multicolumn{6}{|l|}{ Race } \\
\hline Non-Hispanic white & 89.9 & 3.5 & 1.0 & 5.4 & 1.0 \\
\hline Other & 9.1 & 7.2 & $1.32(0.56-3.09)$ & 2.2 & $0.23(0.09-0.64)$ \\
\hline \multicolumn{6}{|l|}{ Marital status } \\
\hline Married/cohabitating & 61.7 & 1.9 & 1.0 & 3.5 & 1.0 \\
\hline Divorced/separated & 12.5 & 8.3 & $4.85(2.23-10.52)$ & 4.6 & $1.21(0.56-2.60)$ \\
\hline Never married & 25.5 & 6.2 & $1.21(0.56-2.60)$ & 9.6 & $2.15(1.10-4.21)$ \\
\hline \multicolumn{6}{|l|}{ Education } \\
\hline$<$ High school & 8.0 & 9.6 & $2.07(0.83-5.15)$ & 12.4 & $3.11(1.25-7.76)$ \\
\hline High school graduate & 29.4 & 3.5 & $1.06(0.47-2.38)$ & 6.9 & $2.06(1.13-3.76)$ \\
\hline >High school & 62.6 & 3.2 & 1.0 & 3.5 & 1.0 \\
\hline \multicolumn{6}{|l|}{ Insurance } \\
\hline Private & 82.4 & 3.4 & 1.0 & 3.9 & 1.0 \\
\hline Public/government & 7.7 & 8.9 & $0.96(0.35-2.60)$ & 5.5 & $0.86(0.38-1.93)$ \\
\hline Uninsured & 9.9 & 3.2 & $0.79(0.24-2.62)$ & 15.5 & $2.84(1.28-6.33)$ \\
\hline \multicolumn{6}{|l|}{ Functional disability } \\
\hline Yes & 17.3 & 8.4 & $3.25(1.65-6.43)$ & 8.4 & $2.39(1.31-6.33)$ \\
\hline No & 82.7 & 2.9 & 1.0 & 4.5 & 1.0 \\
\hline
\end{tabular}

${ }^{a}$ Reporting no IPV is reference category.

$81.8 \%$ who reported psychological IPV. Prevalence of current CBE was $73.3 \%$ among those who reported no IPV, compared with $62.4 \%$ of those who reported physical or sexual IPV and $59.6 \%$ of those who reported psychological IPV. Current Pap smears were more common among those who reported physical or sexual IPV (87.2\%) than among those who reported no IPV $(77.2 \%)$ or psychological IPV (77.0\%). Prevalence of current smoking was $23.4 \%$ among those who reported no IPV, $44.9 \%$ among those who reported physical or sexual IPV, and $34.8 \%$ among those who reported psychological IPV. Among those who reported no IPV, 1.7\% were problem alcohol users, compared with $8.4 \%$ of those experiencing physical or sexual IPV and $5.7 \%$ of those experiencing psychological IPV.

Multivariable logistic regression models assessing the associations of IPV with each of the outcome variables are presented in Table 2 . Physical IPV was positively associated with current Pap smear $(\mathrm{OR}=2.39,95 \%$ CI 1.01-5.70), current smoking status $(\mathrm{OR}=2.07,95 \% \mathrm{CI} 1.03-4.18)$, and high-risk alcohol use $(\mathrm{OR}=4.85,95 \% \mathrm{CI}$ 2.02-11.60). Psychological IPV was positively associated with high-risk alcohol use $(\mathrm{OR}=3.22$, 95\% CI 1.46-7.09).

\section{DISCUSSION}

The reported prevalence of physical IPV in the past year among women ages $18-54$ was $4.1 \%$ in the RI BRFSS. An additional 4.5\% reported experiencing psychological IPV in the absence of physical IPV during this period. Although only a few other states have included questions about IPV in the past year in their BRFSS or similar surveys, Rhode Island's estimate of physical IPV was in the range of those reported by these states. In Massachusetts, the past year prevalence of physical IPV was $2.7 \%$ in $1998,{ }^{6}$ and in New York, it was $5.6 \%$ in $1994 .{ }^{4}$ In studies with designs similar to the BRFSS conducted in Georgia ${ }^{5}$ and California, ${ }^{33} 6.0 \%$ and $6.0 \%$ of women, respectively, reported experiencing physical IPV in the past year. Questions asked to ascertain physical IPV were similar to those included in the RI BRFSS.

Victims of IPV did not differ from nonvictims in use of checkups or CBE, suggesting no differences in access to routine care. In addition, physical IPV victims were more likely than nonvictims to have received a Pap smear within the past year. Given that women who experience physical violence are at increased risk for chronic pelvic pain 
Table 2. Adjusted Logistic Regression Models of IPV and Health

Behavior Outcomes among Rhode Island Women in 1999

\begin{tabular}{|c|c|c|c|c|c|}
\hline & $\begin{array}{l}\text { Current } \\
\text { checkup } \\
\text { OR }(C I)\end{array}$ & $\begin{array}{c}\text { Current } \\
\text { CBE } \\
\text { OR }(C I)\end{array}$ & $\begin{array}{l}\text { Current } \\
\text { Pap smear } \\
\text { OR (CI) }\end{array}$ & $\begin{array}{l}\text { Current } \\
\text { smoking } \\
O R(C I)\end{array}$ & $\begin{array}{c}\text { High-risk } \\
\text { alcohol use } \\
\text { OR (CI) }\end{array}$ \\
\hline \multicolumn{6}{|l|}{ Intimate partner violence } \\
\hline Physical/sexual & $0.70(0.32,1.55)$ & $0.71(0.54,1.54)$ & $2.39(1.01,5.70)$ & $2.07(1.03,4.18)$ & $4.85(2.02,11.60)$ \\
\hline Psychological only & $0.92(0.44,1.94)$ & $0.69(0.54,1.05)$ & $1.52(0.71,3.25)$ & $1.34(0.76,2.37)$ & $3.22(1.46,7.09)$ \\
\hline None & 1.0 & 1.0 & 1.0 & 1.0 & 1.0 \\
\hline \multicolumn{6}{|l|}{ Age, years } \\
\hline $18-29$ & $1.29(0.74,2.24)$ & $0.86(0.56,1.34)$ & $1.90(1.22,2.97)$ & $1.10(0.71,1.71)$ & $4.77(1.94,11.71)$ \\
\hline $30-44$ & $0.88(0.60,1.31)$ & $0.97(0.69,1.63)$ & $1.58(1.12,2.22)$ & $1.23(0.89,1.71)$ & $3.14(1.43,6.92)$ \\
\hline $45-54$ & 1.0 & 1.0 & 1.0 & 1.0 & 1.0 \\
\hline \multicolumn{6}{|l|}{ Race } \\
\hline Non-Hispanic white & 1.0 & 1.0 & 1.0 & 1.0 & 1.0 \\
\hline Other & $1.27(0.72,2.25)$ & $0.67(0.43,1.03)$ & $0.81(0.50,1.32)$ & $0.87(0.55,1.37)$ & $0.70(0.33,1.39)$ \\
\hline \multicolumn{6}{|l|}{ Marital status } \\
\hline Married/cohabitating & 1.0 & 1.0 & 1.0 & 1.0 & 1.0 \\
\hline Divorced/separated & $1.01(0.64,1.57)$ & $1.22(0.83,1.78)$ & $0.91(0.62,1.34)$ & $1.40(0.98,2.00)$ & $1.72(0.92,3.22)$ \\
\hline Never married & $0.76(0.49,1.19)$ & $0.61(0.42,0.87)$ & $0.47(0.32,0.67)$ & $1.44(0.99,2.11)$ & $2.95(1.56,5.58)$ \\
\hline \multicolumn{6}{|l|}{ Education } \\
\hline$<$ High school & $1.23(0.63,2.42)$ & $0.44(0.27,0.71)$ & $0.64(0.37,1.12)$ & $1.60(0.97,2.63)$ & $0.50(0.19,1.32)$ \\
\hline High school graduate & $1.20(0.81,1.77)$ & $0.69(0.51,0.95)$ & $0.71(0.51,0.99)$ & $1.57(1.15,2.13)$ & $0.92(0.54,1.57)$ \\
\hline$>$ High school & 1.0 & 1.0 & 1.0 & 1.0 & 1.0 \\
\hline \multicolumn{6}{|l|}{ Insurance } \\
\hline Private & 1.0 & 1.0 & 1.0 & 1.0 & 1.0 \\
\hline Public/government & $1.73(0.85,3.51)$ & $1.10(0.66,1.83)$ & $1.11(0.65,1.90)$ & $1.56(0.99,2.48)$ & $1.55(0.80,3.00)$ \\
\hline Uninsured & $0.41(0.24,0.70)$ & $0.35(0.22,0.54)$ & $0.29(0.18,0.45)$ & $1.44(0.86,2.41)$ & $1.02(0.42,2.48)$ \\
\hline \multicolumn{6}{|l|}{ Functional disability } \\
\hline Yes & $1.00(0.62,1.59)$ & $1.13(0.76,1.67)$ & $0.91(0.62,1.34)$ & $1.34(0.96,1.87)$ & $0.76(0.38,1.53)$ \\
\hline No & 1.0 & 1.0 & 1.0 & 1.0 & 1.0 \\
\hline
\end{tabular}

and STDs, it is encouraging that women who experienced physical IPV in this study had substantial rates of current Pap smear screening. Although we were unable to assess if women received Pap smear screening specifically because of pelvic pain or if women discussed their abuse histories with their providers, resulting in a recommendation for screening, these findings do indicate proper use of Pap smears by a population at substantial risk. This association was strongest among younger women. Given that women, and younger women in particular, often substitute gynecological visits for routine physical examinations, ${ }^{38,39}$ gynecological visits, whether with a general medicine doctor or a gynecologist, may be an ideal opportunity to assess and counsel younger women for IPV.

Women who experienced physical IPV were also more likely to smoke cigarettes and use alcohol heavily. This is consistent with findings of other studies. ${ }^{6,25,30-33}$ The use of alcohol as a coping mechanism for violence has long been acknowledged. ${ }^{39}$ Although the causal direction of the relationship between smoking and violence has not been studied, there is evidence indicating that smoking often follows stressful situations. ${ }^{40}$ Thus, it is likely that higher rates of smoking observed among victims of IPV are in response to these highly stressful situations.

This study is limited by its cross-sectional design, which does not allow for causality to be inferred between IPV and each of the outcome variables. In addition, the use of self-reported data is problematic because of the threat of social desirability bias. ${ }^{41-44}$ In particular, there is a tendency for research study participants to underreport cigarette smoking and alcohol use and to overreport healthcare use. It is also likely, because of its sensitive nature, that IPV is underestimated. This opens the possibility of differential information bias, in which the association of IPV with smoking and alcohol use is overestimated and the association of IPV with healthcare use is underestimated. Nonresponse bias also poses a threat because of possible systematic differences between those who participated in the RI BRFSS and those who refused participation. In general, persons who are poor, less well educated, uninsured, and seriously ill tend to be underrepre- 
sented in surveys. ${ }^{44}$ As shown in Table 1, each of the subgroups likely to be underrepresented in these datasets is also at greater risk for IPV. Because of the low response rate and likely underascertainment of persons at high risk for IPV, our rates may underestimate the prevalence of IPV.

\section{CONCLUSIONS}

Despite the limitations of the BRFSS data, our findings suggest that women who experience physical or psychological IPV are at increased risk for engaging in negative health behaviors, thus adding additional risks to their health. Our findings also suggest that routine, nonemergency physician visits are opportune times to screen and counsel women who experience IPV. Although healthcare use is common among women who experience IPV and several professional medical organizations have recently begun to endorse screening and counseling for physical IPV ${ }^{45-52}$ healthcare providers have demonstrated reluctance to carry out such screening and counseling. ${ }^{53-55}$ Common reasons for this include the perception that IPV is rare, lack of confidence and discomfort in asking about physical abuse, and feeling powerless to do anything about IPV. Assessment tools for IPV screening currently are available from such organizations as the American College of Obstetricians and Gynecologists, ${ }^{46}$ the American Medical Association, ${ }^{56}$ the Family Violence Prevention Fund, ${ }^{57}$ and American Academy of Family Physicians. ${ }^{58}$ Provider training is needed to improve provider awareness and selfefficacy in screening and counseling female patients for IPV at all routine medical visit. Encouraging the use of available assessment tools would facilitate implementation.

\section{ACKNOWLEDGMENT}

We thank Jana Hesser of the Rhode Island Department of Public Health for her assistance in using the 1999 RI BRFSS.

\section{REFERENCES}

1. Tjaden P, Thoennes N. Prevalence, incidence, and consequences of violence against women: Findings from the National Violence Against Women Survey, Washington, DC: U.S. Department of Justice, Office of Justice Programs, November 1998 (Report No. NCJ 172837).

2. Walker L. The battered woman: A new theory about battered women based on three years of exhaustive case studies. New York: Harper \& Row, 1979.

3. Straus MA, Gelles RJ. Societal change and change in family violence from 1975 to 1985 as revealed by two national surveys. J Marriage Fam 1986;48:465.

4. CDC. Physical violence and injuries in intimate relationships-New York, Behavioral Risk Factor Surveillance System, 1994. MMWR 1996;45:765.

5. CDC. Lifetime and annual incidence of intimate partner violence and resulting injuries-Georgia, 1995. MMWR 1998;47:849.

6. Hathaway JE, Mucci LA, Silverman JG, Brooks DR, Mathews R, Pavlow CA. Health status and health care use of Massachusetts women reporting partner abuse. Am J Prev Med 2000;19:302.

7. Wilt S, Olson S. Prevalence of domestic violence in the United States. J Am Med Wom Assoc 1996;51:77.

8. Walker LE. The battered woman syndrome. New York: Springer, 1999, 2nd edition.

9. Koss MP, Koss PG, Woodruff WJ. Deleterious effects of criminal victimization on women's health and medical utilization. Arch Intern Med 1991;151:342.

10. McLeer SV, Anwar R. A study of battered women presenting in an emergency department. Am J Public Health 1989;79:65.

11. Goldberg WG, Tomlanovich MC. Domestic violence victims in the emergency department. JAMA 1984; 251:3259.

12. Abbott J, Johnson R, Koziol-McLain J, Lowenstein SR. Domestic violence against women: Incidence and prevalence in an emergency department. JAMA 1995; 273:1763.

13. Muelleman RA, Lenaghan PA, Pakieser RA. Battered women: Injury locations and types. Ann Emerg Med 1996:28:486.

14. Dearwater SR, Coben JH, Campbell JC, et al. The prevalence of intimate partner abuse in women treated at community hospital emergency departments. JAMA 1998;280:433.

15. Coker AL, Smith PH, Bethea L, King MR, McKeown RE. Physical health consequences of physical and psychological intimate partner violence. Arch Fam Med 2000;9:451.

16. Rapkin AJ, Kames LD, Darke LL, Stampler FM, Naliboff BD. History of physical and sexual abuse in women with chronic pelvic pain. Obst Gynecol 1990; 76:92.

17. Drossman DA, Lesserman J, Nachman G. Sexual and physical abuse in women with functional or organic gastrointestinal disorders. Ann Intern Med 1990;113: 828.

18. Straus MA, Gelles RJ. Physical violence in American families: Risk factors and adaptations to violence in 8,145 families. New Brunswick, NJ: Transaction, 1995. 
19. Geist RF. Sexually related trauma. Emerg Med Clin North Am 1988;6:439.

20. Forster GE, Estreic S, Hooi YS. Screening for STDs. Ann Emerg Med 1991;324:161.

21. Lacey HB. Sexually transmitted diseases and rape: The experience of a sexual assault centre. Int J STD AIDS 1990;1:405.

22. Murphy SM. Rape, sexually transmitted diseases and human immunodeficiency virus infection. Int J STD AIDS 1990;1:79.

23. Rath GD, Jarratt LG, Leonardson G. Rates of domestic violence against adult women by men partners. J Am Board Fam Pract 1989;2:227.

24. Haber J. Abused women and chronic pain. Am J Nurs 1985;85:1010.

25. Tech C, Lindquist C. Violent vs. non-violent couples: A comparison of patterns. Psychotherapy 1984;21:242.

26. Van Hightower NR, Gorton J. Domestic violence among patients at two rural health care clinics: Prevalence and social correlates. Public Health Nurs 1998; 15:355.

27. Tollestrup K, Sklar D, Frost FJ, et al. Health indicators and intimate partner violence among women who are members of a managed care organization. Prev Med 1999;29:431.

28. Bergman B, Brismar B. A 5-year follow-up study of 117 battered women. Am J Public Health 1991;81:1486.

29. Koss MP, Koss PG, Woodruff MS. Deleterious effects of criminal victimization on women's health and medical utilization. Arch Intern Med 1991;151:342.

30. Verhoek-Oftedahl W, Pearlman DN, Coutu Babcock J. Improving surveillance of intimate partner violence by use of multiple data sources. Am J Prev Med 2000;19:308.

31. Amaro H, Fried LE, Cabral H, Zuckerman B. Violence during pregnancy and substance abuse. Am J Public Health 1990;80:575.

32. Miller BA, Downs WR, Gondoh DM. Spousal violence among alcoholic women as compared to a random household sample of women. J Stud Alcohol 1989;50: 533.

33. Weinbaum Z, Stratton TL, Chavez G, MotylewskiLink C, Barrera N, Courtney JG. Female victims of intimate partner physical domestic violence (IPP-DV), California 1998. Am J Prev Med 2001;21:313.

34. Council of American Survey Research Organizations. On the definition of response rates. CASRO Publications, Port Jefferson, NY. Special Report, 1982.

35. U.S. Preventive Services Task Force. Guide to clinical preventive services, 2nd ed. Baltimore: Williams \& Wilkins, 1996.

36. U.S. Department of Health and Human Services (DHHS). Physicians' guide to helping patients with alcohol problems. NIH Pub. No.95-3769, Washington DC: DHHS, Public Health Service, 1995.

37. Horton JA, Cruess DF, Pearse WH. Primary and preventive care practices provided by obstetrician-gynecologists. Obstet Gynecol 1993;82:723.

38. Hendrix SL, Piereson SD, McNeeley SG. Primary care and preventive care in a university obstetrics and gynecology group practice. Am J Obstet Gynecol 1995; 172:1719.

39. National Institute on Alcohol Abuse and Alcoholism (NIAAA). Alcohol, violence and aggression. Alcohol Alert No. 38, Rockville, MD: National Institutes of Health, 1997.

40. Vollrath M. Smoking, coping and health behavior among university students. Psych Health 1998;13:431.

41. Gordon NP, Hiatt RA, Lampert DI. Concordance of self-reported data and medical record audit for six cancer screening procedures. J Natl Cancer Inst 1993; 85:566.

42. Wagenknecht LE, Burke GL, Perkings LL, Haley NJ, Friedman GD. Misclassification of smoking status in the CARDIA study: A comparison of self-reports with serum cotinine levels. Am J Public Health 1992;81:33.

43. Embree BG, Whitehead PC. Validity and reliability of self-reported drinking behavior: Dealing with the problem of response bias. J Stud Alcohol 1993;54:334.

44. Aday L. Designing and conducting health surveys, 2nd ed. San Francisco, CA, Josey-Bass, 1996.

45. American College of Emergency Physicians. Emergency medicine and domestic violence. Ann Emerg Med 1995;25:442.

46. American College of Obstetricians and Gynecologists (ACOG). Domestic violence. ACOG Tech. Bull. 209. Washington, DC: ACOG, 1995.

47. American College of Nurse Midwives. Position statement on violence against women. Washington, DC: American College of Nurse Midwives, August 1997.

48. American Nursing Association. Position statement: Physical violence against women. Washington, DC: American Nursing Association, September 1991.

49. Council on Scientific Affairs, American Medical Association. Violence against women: Relevance for medical practitioners. JAMA 1992;267:3184.

50. Emergency Nurses Association. Position statement: Domestic violence. Park Ridge, IL: Emergency Nurses Association, 1994.

51. Joint Commission on Accreditation of Healthcare Organizations. Accreditation manual for hospitals. Vol 1. Standards. Oakbrook Terrace, IL: Joint Commission on Accreditation of Healthcare Organizations, 1992:21.

52. U.S. Department of Health and Human Services (DHHS). Healthy people 2000: National health promotion and disease prevention objectives. DHHS Pub. No. PHS 91-50212. Washington, DC: DHHS, Public Health Service, 1991:237.

53. Sugg NK, Thompson RS, Thompson DC, Maiuro R, Rivara FD. Domestic violence and primary care: Attitudes, practices and beliefs. Arch Fam Med 1999;8:301.

54. Sugg NK, Inui T. Primary care physicians' response to domestic violence: Opening Pandora's box. JAMA 1992;267:3157.

55. Waalen J, Goodwin MM, Spitz AM, Petersen R, Saltzman LE. Screening for intimate partner violence by health care providers: Barriers and interventions. Am J Prev Med 2000;19:230. 
56. American Medical Association. American Medical Association's diagnostic and treatment guidelines on domestic violence. Arch Fam Med 1992;1:39.

57. Family Violence Prevention Fund. Preventing domestic violence: Clinical guidelines on routine screening. San Francisco, CA, 1999.

58. Eyler AE, Cohen M. Case studies in partner violence. Am Fam Phys1999;60:2569.
Address reprint requests to:

Stephenie C. Lemon, Ph.D.

University of Massachusetts Medical School Division of Preventive and Behavioral Medicine 55 Lake Avenue North Worcester, MA 01655

E-mail: stephenie.lemon@umassmed.edu 